\title{
Peywendiya Mîr û Mela di Çarçoveya Patronaja Edebî de
}

\section{Zülküf ERGÜNi}

\begin{abstract}
Kurte: Di vê gotarê de peywendiya Melayê Cizîrî û Mîrê Cizîra Botan di çarçoveya patronaja edebî de tê vekolîn. Ji bo vê mebestê piștî ku taybetmendiyên patronaja edebî û nasnameya patronê Melayê Cizîrî tê ronkirin bi rêya helbestên wî peywendiya wî ya digel Mîrê Cizîra Botan tê berçavkirin. Di encamê de di vê gotarê de tê nîşandan ku Melayê Cizîrî bi çendîn helbestên xwe pesnê hêz, desthilat û comerdiya mîrên Cizîra Botan daye û wek helbestvanekî serayê hunera xwe xistiye bin xizmeta mîran û di beramber vê de jî ji aliyê wan ve hatiye padaştkirin. Ji ber vê dema şanazî bi hunera helbesta xwe dike di heman demê de xurûra seraya patronê xwe jî temsîl dike û bi vî awayî yekem mînaka patronaja edebî pêşkêş dike di edebiyata kurdî de.
\end{abstract}

Bêjeyên Sereke: Patronaj, qesîde, Mîr, Mela.

\section{Edebi Patronaj Çerçevesinde Mîr ve Mela İlişkisi}

Öz: Bu makalede edebî patronaj çerçevesinde Melayê Cizîrî ve Cizîra Botan Emîrî ilişkisi ele alınmaktadır. Bu amaçla edebî patronajın özellikleri ve Melayê Cizîrînnin patronunun kimliği konuları izah edildikten sonra seçilen şiirlerin içerik analizi yoluyla Melayê Cizîrî ile Cizîra Botan Emirî ilişkisi ortaya konmaktadır. Sonuç olarak bu makalede Melayê Cizîrî̀nin bazı şiirlerinde Cizîra Botan Emiri'nin gücü, iktidarı ve cömertliğini övdüğü, bir saray şairi olarak sanatıyla emirlerin hizmetine girdiği ve bunun karşılığında da bu emirler tarafından ödüllendirildiği gösterilmektedir. Bundan dolayı kendi şiir sanatıyla övünürken aynı zamanda patronunun sarayının gururunu temsil ettiği ve Kürt edebiyatında ilk edebî patronaj örneğini sunduğu vurgulanmaktadır.

Anahtar Sözcükler: Patronaj, kaside, Mîr, Mela. 


\title{
The Relation between Mîr (Head) and Mela on the Frame of Literary Patronage
}

\begin{abstract}
In this article, the relation between Melayê Cizîrî and head of Cizîra Botan are considered in the context of literary patronage. For this purpose, after the features of literary patronage and the identity of Melayê Cizîrî's boss were explained, the relation between Melayê Cizîrî and head of Cizîra Botan are revealed through content analysis of chosen poems. As a result, it is shown in this article that Melayê Cizîrî praised head of Cizîra Botan' power, generosity and his political power in his some poems. Additionally, Melayê Cizîrî as a palace poet entered into the heads of Cizîra Botan services with his art and he was rewarded by the Mîrs/heads. Therefore, it is emphasized that while the Mela was boasting his own potry's art, at the same time he glorified the pride of the boss's palace and in this way, the first liteary patronage example in Kurdish literary is offered.
\end{abstract}

Key Words: Patronage, eulogy, Mîr/head, Mela.

\section{Destpêk}

Erkên edebiyatê li gor serdem û rêbazên ciyawaz hertim di nav guherînê de bûye. Bêguman yek ji van erkan jî erka bangeşe (propaganda) û sûdparêziya (pragmatîzm) edebiyatê ye ku di çarçoveya sûda takekesî, civakî û siyasî de ji bo xizmetkirina armancên diyarkirî derdikeve holê. Bi taybetî di serdemên hikumraniya xanedanan de edebiyat bi vê erka xwe dikeve bin barê pesindana hikumdaran û di beramber de jî derfetên bilindbûn û karîyerê ji bo edîb û helbestvanan dabîn dike. Ev têkiliya patrîmonyal dema ku ji bo helbestvanan deriyê îqbalê vedike ji bo hikumdaran jî zemîna bangeșe û reklamê saz dike û bi vî awayî sûdeke dualî encam dide. Digel vê yekê di navbera helbestvan û hikumdaran de têkiliyeke asîmetrîk heye ku hertim hikumdar wek çavkanî û navenda hêz û desthilatê, xwedî serwerî û otorîteyeke reha ne û helbestvan jî peyk û perwaneya cazîbeya hikumdar in. Ji ber vê hejmûna hikumdaran jî li hin welatên mîna Îngiltereyê qonaxên edebî jî bi navê şahbanûyên mîna Elizabeth û Victoriayê tên binavkirin (Wellek-Warren, 2013: 311) û sîstema patronaja edebî bi navê wan tê sembolîzekirin.

Li gor çavkaniyên berdest peywendiyên patronajê di edebiyata kurdî de cara pêşî di mînaka Melayê Cizîrî (1567-1640) û mîrên Cizîra Botan de tê dîtin. Mela bi du qesîde, danberhevek (muşa'ara) û çendîn xezelên xwe berê hunera xwe dide mîran û dibe danerê edebiyata pesindariyê di helbesta kurdî de. Bêguman ev diyarde di serdema Melayê Cizîrî de normeke cîhanî bû û mirov dikare bibêje ku yek ji hokarên sereke yên berhemanîna edebî bû. Ji ber vê gelek helbestvan û edîbên wê serdemê bi mebesta gihîștina armancên xwe ji serayekê bo serayeke din diçûn û ji ku derê piştevaniyeke bihêz bidîta li wê derê cih digirt û hunera xwe ji bo pesindana wî hikumdarî bi kar dianî. Hikumdaran jî bi mebesta têrkirina hesta xwe ya estetîkî, bihêzkirina pêgeha xwe ya siyasî û belavkirina navdariya xwe xwedîtî li helbestvanan dikir û ji hêza hunera wan sûd werdigirt.

Melayê Cizîrî wek helbestvanekî nîvê duyem ê sedsala şanzdehan û nîvê yekem ê sedsala huvdehan, di serdema hikumraniya mîrên Azîzan de li Cizîra Botan 
dijî, di nav sîstemeke patrîmonyal de helbestên xwe berhem tîne û di dahênana wî ya edebî de roleke berbiçav a patronaja edebî çê dibe. Tevî vê yekê, ji ber nebûna agahiyên bibelge derbarê jiyana Melayê Cizîrî de û bidestneketina tomarên nivîskî yên mîrektiya Cizîra Botan em derbarê jiyana Mela de xwedî zanyariyên teqez nînin û em nizanin bê Melayê Cizîrî heta çi radeyê piştgirî ji dezgehên mîrektiyê wergirtiye. Lê cihê gora wî ya ku di nav goristana taybet a malbata Mîr de ye (di Mizgefta Sor de), hin zanyariyên nav helbestên wî û ragihandinên nav gel derdixin ku peywendiyeke bihêz a Melayê Cizîrî bi seraya mîrên Cizîra Botan re hebûye (Ergün, 2014: 128-132) û di çarçoveya patronaja edebî de xwe spartiye desthilata wan.

Di vê gotarê de em dê di pêngava pêşî de derbarê çavkaniya patronaja edebî û peywendiyên helbestvan û hikumdaran de agahî bidin, piştî vê jî ji ber ku derbarê muxatebê her du qesîdeyên pesinnameyî yên Mela de nêrînên ciyawaz hene em dê hewl bidin muxatebê rasteqîne yê van qesîdeyan destnîşan bikin. Li dû vê, em dê bi şîrovekirina naveroka her du qesîdeyên Mela peywendiya patronajî ya Mîr û Mela berçav bikin. Herweha li dor danberheva Mîr û Mela em dê behsa peywendiyên nêzîk ên Mela û Mîr û hogiriya wan bikin. Herî dawî em dê şanaziya Mela ya helbestî di nav tora peywendiyên patrojana edebî de şîrove bikin.

\section{1. Çavkaniya Patronaja Edebî}

Ji destpêka avakirina rêvebiriyên monarşîk heta jinavçûna vê sîstemê hikumdar ne tenê çavkanî û navenda desthilata siyasî û aborî ne, di heman demê de bi kesayeta xwe ya egosantrîk qîble û armanca sereke ya edebiyat û hunerê ne jî. Lewra di sîstema patrîmonyal de hikumdar di lutkeya pîramîda hiyerarşiya desthilatdariyê de cih digirin û bi hêzeke reha weku rojê li ser her tișt û her kesî hikum dikin. Çawa ku di mînaka Destana Gilgamêșê û bajarên Sumerê de jî tê dîtin dema hikumdar li hember xwedawendên perestgehê û zilamên dînî têdikoşin û hêza wan lawaz dikin di hemû warên jiyanê de dibin tekane hêz û otorîteya rêvebiriyê û her tiştî dikin bin kontrola xwe. Piştî vê serkeftinê hemû pîroziyên xwedawendan derbasî hikumdaran dibin û her hikumdarek mîna xwedawendekî xwe bihêz û xwedî keramet dizane. Ji ber vê çendê, hikumdarên pêşî weku tekane çavkaniya rewatiya rêvebiriyê, di kesayetiya xwe de hemû beșên jiyanê, welat û hemwelatiyan temsîl dikin (Mumford, 2007: 54) û bi vî awayî li ser mirovan otorîteya xwe ya reha disepînin.

Ji ber van hokaran û piştî damûdezgehkirina sîstema dewletdariyê hikumdar wek navendeke cazîbeyê her tiştî û hemû hêzên şaristaniyê li dora seraya xwe dicivînin (Mumford, 2007: 51-52) û li dor vê sîstemê xwe dikin çavkaniya hemû hêz, îhsan û hunerê û herkesî mîna peykan li dora roja hikumdariya xwe digerînin. Ji ber vê jî Lapidus peydabûna patronaja edebî bi kesayeta hikumdaran ve girê dide û diyar dike ku "bi rêya vê parastinê hikumdaran huner û edebiyat weku neynika erêkirina xanedaniya xwe ya narsîstî bi kar dianîn û bi rêya helbestvanan, seraya xwe weku bihişt, hukmê xwe cîhanî û kesayetiya xwe weku sîbera Xwedayî nîşan didan" (Lapidus, 2005: 136). Her di vê çarçoveyê de mîna ku Ahmet Yaşar Ocak 
ji Cahen radigihîne Fexreddîn Behramşah ji aliyê sultanan ve sedema xelatkirina helbestvanan weha derdibirîne: "Eger helbest serkeftî be ez dê xezîne û defîneyan bibexşînim. Lewra bi vê pirtûka menzûm dê navê min di vê cîhana fanî de hertim bimîne. Di vê cîhana fanî û demkî de jibîrnebûn û mayîna navê mirov îtîbareke mezin û serkevtineke hêja ye" (Ocak, 2011: 306). Ji ber vê çendê jî, hîn di bajarên pêşî yên Mezopotamya û Misirê de li serayên hikumdaran helbestvan û edîbên serayan peyda dibin û bi vî awayî demeke dirêj edebiyat û bi taybetî helbesta serayê li dor pesindana kesayetiya hikumdaran û hêvî û daxwazên jiyana wan tê hûnandin.

Di cîhana îslamê de jî piştî damezirandina dewletên Emewî û Ebbasî edebiyateke xurt a serayê derdikeve holê û gelek helbestvan û edîb li dora serayê dicivin. Di vê serdemê de edebiyat heta radeyeke baş karê çîneke diyarkirî ya mîna rêvebir û karmendên resmî ye ku ev kesayet xwe dispêrin otorîteya xelîfe. Lê di nav demê de ji bilî van kesayetan hinek zanyarên medreseyan jî bi mebesta teltîf û tewecuha hikumdaran û civakê di nav van edîbên serayê de cihên xwe digirin (Hodgson, 1993: 426). Lewra di nav sîstema monarşîk a dewletên berê de tekane rêya xwe gihandina pile û payeyên bilind ên civakî û dabînkirina jiyaneke baş bidestxistina îltîfat û îhsana hikumdaran û çîna serdest bû. Ji ber vê çendê, helbestvan û edîb bi armanca gihîștina parastina hikumdarên xwedî mulk û bidestveanîna rizamendiya rêvebirên bihêz, berê xwe didin serayê. Lê divê mirov vê jî bizane ku di peywendiya edîb û serayê de patronaj û parastin ji hewcedariyeke du-alî pêk dihat. Lewra çawa ku helbestvan û edîb bi saya parastina hikumdar û serayê dibûn xwedî şan, şeref û pere; her weha hikumdar jî bi rêya van edîb û zanyaran nav û nîşanên xwe mezin dikirin (İnalcık, 2010: 13). Ji ber vê çendê jî piraniya helbestvan û edîbên baş xwe dispêrin hîmayeya hikumdarekî û bi saya vê berjewendiya du-alî berhemên hêja li dû xwe dihêlin. Ji ber vê jî bi gotina George Makdîsî bextê edebiyatê rasterast bi bextê hikumdaran ve tê girêdan û bi bilindbûn û daketina xanedanan edebiyat jî bilind dibe û dadikeve (Makdisi, 2009: 284).

Di nav vê norma cîhanî de piştî derketina mîrektiyên kurdî di dawiya serdema Ebasiyan de di nav kurdan de jî dîwan û navendên rêvebiriyê peyda dibin û ev dîwan jî wek nimûneyên biçûk ên dîwanên paytexta xelîfetiyê tên rêkxistin. Di van dîwanan de jî kesên zana, edîb û rayedar kom dibin û di birêvebirina karûbarê mîrektiyê de rol dibînin (Ebûş, 2004: 89). Ji ber vê rola wan a girîng jî ev kesayet weku unsûrên jêneger ên rêvebiriyê tên qebûlkirin û ji ber pêdiviyên burokratîk ji aliyê mîrekan ve tên parastin. Di encama vê parastinê de jî li ser destê van kesan berhemên îlmî û edebî derdikevin holê û serayên wan dibin navendên peydabûna berhemên edebî ku Cizîra Botan yek ji van navendan e.

\section{Melayê Cizîrî Wek Helbestvanekî Mîrektiya Cizîra Botan}

Ji destpêka bajar-dewletan heta bicihbûna damûdezgehên modernîteyê hem li rojhilat hem jî li rojavayê navendên herî bihêz ên huner û edebiyatê serayên hikumdaran bûne û her seray li gor hêza hikumdarê xwe bûye navenda dahênana edebî û hunerî. Di vê çarçoveyê de seraya Mîrektiya Cizîra Botan yek ji serayên herî 
bihêz ên mîrên Kurdistanê bûye û di derketina helbestvanekî mîna Melayê Cizîrê de kartêkeriyeke berçav a vê serayê hebûye. Di dîwana Melayê Cizîrî de çendîn helbest hene ku peywendiya Melayê Cizîrî digel seraya Cizîra Botan berçav dikin. Bi taybetî her du qesîdeyên wî yên ku ji bo pesindana Mîrê Cizîra Botan hatine nivîsîn, nîşaneyên bihêz ên vê peywendiyê ne. Lewra qesîdeyên pesindanê di eslê xwe de cure helbestên serayê ne û ji bo bidestxistina îltîfata hikumdaran tên nivîîn. Weku Halil İnalcık jî dibêje di edebiyata rojhilatê de lêgerîna hîmaye û arîkariyê bi rêya pêşkêşkirina qesîdeyan xwe nîşan dide (İnalcık, 2010: 23) û nivîsîna qesîdeyan jî zêdetir karê helbestvanên serayê ye. Loma jî ev her du qesîdeyên Melayê Cizîrî nîșan didin ku Mela helbestvanekî serayê bûye û xwe sipartiye hîmayeya Mîrê Cizîra Botan.

Ji van her du qesîdeyên Melayê Cizîrê yek jê bi malika "Xanê xanan lami'ê necma te her purnûrî bî/ Keștiya bextê te ez bayê muxalif dûrî bî" dest pê dike. Herçend Melayê Cizîrî di qesîdeya xwe de navê Mîrê Cizîra Botan aşkera nekiribe jî cih dide navê paytexta Mîr û Cizîrê weku "paytexta heft îqlîman” raber dike. Ji ber vê çendê tu guman tê de namîne ku ev qesîde ji bo pesindana Mîrê Cizîra Botan hatiye gotin. Mela bi vê malikê seraya Mîrê Cizîra Botan wek navenda hemû cîhanê dide zanîn û patronê xwe mezin dike.

\section{Ma Cizîrê şubhê darê textê heft iqlîmi bit \\ Hem bi hukm û seltenet Eskender û Fexfûrî bî (Cizîrî, 2010: 224)}

Qesîdeya duyem a Melayê Cizîrî bi malika "Ey şehinşahê mu'ezzem Heq nigehdarê te bî/ Sûreê "Înna Fetehna" dor û madarê te bî" dest pê dike. Li ser muxatebê vê qesîdeya Mela di nav lêkolerên edebiyata kurdî de fikrên ciyawaz peyda bûne. Lewra ev kes, bê ku tevahiya qesîdeyê û rastiyên dîrokî li ber çav bigirin, ji hin malikên ku ji bo pesindanê hatine gotin, encamên nerast derxistinine. Bo nimûne:

Ney tinê Tebrîz û Kurdistan li ber hukmê te bin

Sed wekî şahê Xurasanê di ferwarê te bî (r. 222)

Eladîn Secadî jî di Mêjûy Edîbî Kurdîya xwe de muxatebên van her du qesîdeyên Melayê Cizîrî ji Sultan Huseyn Baykarayê Teymûrî yê hikumdarê Îranê û Sultan Fatîh û Bayezîdê Duyemê Osmanî yekî dizane (Secadî, 1952: 159-160). Herweha ji ber ku di serdema Sultan Selîm de di şerê Çaldiranê de Sefewî tên şikandin û Tebrîz ji aliyê hêzên Osmanî ve tê dagîrkirin ev malik Sultan Selîmê Osmanî û ji ber kudi serdema Sultan Suleyman û Sultan Muradê Çarem de li dijî Eceman sefer tên lidarxistin û dewleta Sefewî bi destê van sultanan tê şikandin heman malik Sultan Suleyman û Sultan Murad bi bîr bîne jî (Doru, 2016: 21), bi raya me ev boçûn û îhtîmal ji rastiyê dûr in. Lewra Fatîh Sultan Mehemed di 1512an de, Sultan Selîm di $1520 i ̂$ de Sultan Suleyman jî di 1566an de dimirin. Ji ber vê çendê 
di serdema Fatîh Sultan Mehemed û Sultan Selîm de hêja Melayê Cizîrî nehatiye dunyayê û di sala mirina Sultan Suleyman de jî Melayê Cizîrî ji dayîk bûye. Ji ber vê jî dîroka hikumraniya van sultanan û jiyana Melayê Cizîrî hev nagirin. Li aliyê din eger Melayê Cizîrî helbesta xwe ji bo Sultanê Osmanî binivîsanda divê yan bi osmanî yan bi farisî yan jî bi erebî binivîsanda, lewra zimanên carî yên wê serdemê ev ziman bûn û bi kurdî heta wê demê ew çend berhemên edebî nehatibû nivîîn. Ji ber vê çendê, herçend serdema jiyana Mela û Sultan Muradê Çarem hev bigirin jî em bi rehetî dikarin bibêjin ku ev qesîde jî mîna qesîdeya pêşî ji bo Mîrê Cizîra Botan hatiye nivîsîn. Lewra ev malika jêrîn cihê hukmê kesê ku tê pesinandin bi aşkerayî nîşan dide.

Ger çi der iqlîmê rabi' hate textê seltenet

Padişahê hefti iqlîman selamkarê te bî (r. 222)

Ji vê malikê derdikeve ku kesê tê pesinandin paytexta wî di îqlîma (herêm) çarem de ye. Li gor zanista coxrafyaya berê mîna ku İbn Haldun jî dibêje Cizîr dikeve îqlîma çaran û beşa şeşan, lê Stenbola ku paytexta dewleta Osmanî bû di îqlîma pêncan û beșa çaran de bû (ibn Haldun, 1991, 313, 319). Ev agahî jî piştrast dike ku muxatebê vê qesîdeyê ne Sultanê Osmanî ye, Mîrê Cizîra Botan e. Dîsa her ji ber vê peyva "Tebrîz"ê ya ku di malika navborî de derbas dibe, li gor veguhestina Hejar, Mehemed Emîn Zekî Beg muxatebê vê qesîdeyê Îmaduddîn Zengî zaniye ku di wê serdemê de Tebrîz di bin hukmê wî de bûye. Lê bi boçûna Hejarê şîrovekarê dîwana Melayê Cizîrî, navê Tebrîzê tu carî nabe delîl ku muxatebê vê qesîdeyê fermanrewayê Tebrîzê be. Lewra Mela ji Xweda xwestiye ku ew mîrê kurd ê Cizîrê ku rewac daye îslamê û feqî û melayên wî gelek hene û dersên Quran û hedîsan dibêjin, Xweda wî baladesttir bike û wî bike xwediyê heft îqlîman. Ji ber vê jî ji Xwedê hêvî kiriye ku ne tenê mulkê Kurdistanê, Tebrîz jî bê ser hikumeta wî û xwediyê mulkê Xorasanê xwe bide ber daldeya wî (Hejar, 1361: 16-21). Mela Ehmedê Zivingî jî bikaranîna peyva "Tebrîz"ê bi mubalexeya helbestê ve girê dide û muxatebê qesîdeyê Mîrê Cizîra Botan dizane (Zivingî, tîpa yê). Jixwe qafiyeya vê qesîdeyê ku bi peyva "bî"yê hatiye çêkirin di seranserê qesîdeyê de bi wateya hêvî û niyazê tê bikaranîn û ji halê mewcud zêdetir daxwaza Mela nîșan dide.

Mela Ehmedê Zivingî (?), Sadiq Behaedîn Amêdî (1998) û Abdullah Yaşın (2007) radigihînin ku ev qesîde ji bo Xan Şerefê Mîrê Cizîra Botan hatiye nivîsîn. Lewra Xan Şeref, di nav mîrên Cizîra Botan de navdartirîn mîr e û di dîroka vê mîrektiyê de xwedî cihekî taybet e. Ji ber rizgarkirina Cizîrê ji bin dagîrkariya Aqqoyîniyan û berxwedana li hember Sefewiyan li gor jêderên dîrokî menqîbeyên rêvebiriya dadperwer a Mîr Şeref di nav xelkê de dibe çavkaniya gelek çîrok û serpêhatiyên qehremaniyê (Sevgen, 1982: 54). Lê çavkaniyên dîrokî aşkera dikin ku Mîr Şerefê Duyem ku bi nasnavê Xan Şeref tê nasîn berî şerê Çaldiranê, di sala 1509an de miriye (Varlî, 1997: 345) û 57 sal berî jidayîkbûna Mela çûye ser heqiya xwe. Jixwe li gor Şerefxan Bedlîsî (2007) di 1597an de li ser textê Mîrektiya Cizîra Botan Mîr Şerefê Sêyem rûniştiye. Ji ber vê çendê jî, ew delîlên ku kesayetên 
navborî ji bo Xan Şeref tînin di heman demê de ji bo Mîr Şerefê Sêyem jî derbas dibin û rasterast ji Xan Şeref re nabin delîl.

Bi dîtina me ji bo diyarkirina muxatebên qesîdeyên Melayê Cizîrî du tişt girîng in, ew jî serdema jiyana Mela û diyarkirina mîrên wê serdemê ne. Herçend derbarê serdema jiyana Mela de fikrên ciyawaz hebin jî fikra herî maqûl û rast ew e ku Melayê Cizîrî di navbera salên 1566/1567 û 1640î de jiyaye. Li aliyê din li gor ragihandina Şerefxan ku berhema xwe di 1597an de temam kiriye mîrê Cizîra Botan ê wê demê Mîr Şerefê Sêyem e. Loma jî bi dîtina me yek ji muxatebên muhtemel ên van her du qesîdeyên Mela, ev mîr e. Lewra dema mirov li salixdanên Şerefxan ên derbarê Mîr Şerefê Sêyem dinêre ev qenaet li cem mirov bihêztir dibe.

Emîr Şeref, ji mîrên hilbijartî û tekmêr ên xanedana mezin a Fermanrewayê Cezîrê yê herîmezin e. Çunkîdi meydana merdî, mêrxasî û alîkariyê de ji emsal û dijminên xwe yên di vî warî de serdesttir e. Di meydana merdan de bi kaşoyê mêraniyê gog ajotiye û sebebên rêz û payeyiyê hemî ji xwe re girtiye. Qehra zendên wî yên bivirî û şûrê wî yê tûj û birekî, tev delîl û îsbatên hêjayetî û serdestiyên mêr û mêrxasiyên wî yên ketina ceng û şeran in. Wekî şair gotiye:

Di dema merdîtî, Xatem tama ye, çiloz e, bê mecal

Di ceng û şer de, henekan dike bi Rustemê Zal

A herî rast ew e ku, re'aya û esker ji dadwerî û qenciyên wî razî ne û ji fikir û xebatên wî spasdar û minnetdar in ji kirinên wî yên mirovane dilxweş û şad in. Ji ber vê jî ji aliyê giregir û mezinan, kesên di rêzê de, kesên nêzîk û dûr her kesî ve tê hezkirin. Hemî ev kesên han her wext ji Xwedê hêvî û lava dikin ku vî mîrê jîr û jêhatî ji wan re biparêze (Bedlîsî, 2007: 239).

Ji van salixdanên Şerefxan mirov têdigihîje ku Mîr Şerefê Sêyem ji aliyê Cizîriyan ve gelek hatiye hezkirin û ji ber ku serdema hikumraniya wî rastî salên kemalê yê Melayê Cizîrî tê, maqûltir e ku mirov bibêje Mela qesîdeyên xwe pêșkêşî vî mîrî kirine. Lewra malika dawî ya vê qesîdeyê jî nîşan dide ku ew Mîrê ku qesîde ji bo wî hatine pêşkêşkirin sax e û Mela hêvî dike hertim di xizmeta wî de be.

Qest û daxwaza Melê daîm ji can û dil ev e

Her di benda xizmetê pêşdestê dîdarê te bî (r. 223)

Diyar e, bi pêşkêşkirina van qesîdeyan, Melayê Cizîrî dikeve bin parastina Mîrê Cizîra Botan û bi îhtîmaleke mezin piştî vê yekê, Mela weku muderisê Medresaya Sor tê destnîşankirin. Lewra bi gotina İnalcık dema helbestvanekî qesîdeyek pêşkêşî hikumdarekî bikira, arîkariya hikumdar xwe bi awayên ciya ciya nîşan dida. Hikumdar li gor pîşeyê wî helbestvanî eger munşî bûya ew dikir 
katib, eger ji çîna ulemayan bûya yan ew weku muderis yan jî weku qazî tayîn dikir (İnalcık, 2010: 28). Xuya ye ku Mîrê Cizîra Botan jî li hember van qesîdeyên wî, Mela bi muderisiya medreseya herî mezin a Cizîrê ku Medreseya Sor bûye padaşt kiriye ew xistiye bin parastina xwe. Ji xwe sîstema parastinê ne tenê li serayên padîşahên mezin di koşkên paşa û mîran de jî dihat dîtin. Hêjayê gotinê ye ku her du helbestvanên mezin ên îranî Se'dîyê Şîrazî (1213-1292) û Hafizê Şîrazî (1315-1390) jî xwedî patronên weha bûn û Ebu Bekirê Salguriyê patronê Se'dî û Ebû Îshaqê Încû û Şah Şuca‘yê Muzaferiyê patronên Hafiz jî ew çend navdar û xwedî desthilateke berfireh nebûn (İnalcık, 2017: 25,28).

\section{Mîrê Bihêz û Melayê Lawaz}

Cewher û binyada helbestên pesindariyê li ser mezinkirin û bilindkirina kesayeta hikumdaran, berçavkirina hêz û şiyana wan û nîşandana lawazî û hewcedariya helbestvanan tê avakirin. Helbestvan bi armanca bidestxistina parastin û arîkariya hikumdar bi teşbîhên curbicur berziya hikumdar û nizmiya xwe berçav dike da ku bigihîje armanca xwe. Melayê Cizîrê jî bi her du qesîdeyên xwe doza hîmayekirinê li Mîrê Cizîra Botan dike û hewl dide bikeve bin xizmet û parastina wî. Ji ber vê jî Mîr dișibîne rojê, asîtana dergehê wî weku cihê bidestxistina dewletê destnîşan dike û bi vî awayî hikumdar weku çavkaniya hêz û îhsanê û xwe jî bende û muhtacê wê hêz û îhsanê raber dike.

\section{Lew ziyaret asîtanê tête şemsa dewletê}

Da sehergahan ji dîdarê şerîf purnûri bî (r. 224)

Di vê malikê de xuya dibe ku seray; navend û çavkaniya ronahî, feyz û îhsanê ye û bi îradeya hikumdar ve girêdayî ye, helbestvan jî perestişkar û daxwazkarê vê feyz û ronahiyê ye. Eger helbestvan bi dîdara Mîr şad û şerîf bibe wê demê ne tenê seher, dê helbestvan jî "purnûr” bibe. Bi vî awayî Mela, weku çavnêr û hewcedarê lutfa Mîr, bi vê malikê rasterast daxwaza parastinê lê dike. Li aliyê din bi hêmayeke hevbeş a helbesta klasîk Mîr dişibîne rojê û mezinahiya wî berçav dike. Lewra mîna ku Ahmet Hamdi Tanpınar jî dibêje di nav xeyalên helbestî yên Serdema Navîn de hikumdar hertim bi rojê hatiye şibandin û mîna rojê ronahî li derûdora xwe belav kiriye (Tanpınar, 2010: 23). Ev jî nîşan dide ku Mela jî mîna helbestvanên din ên rojhilatî ji ber ku Mîr weku şah û padisşahên din, navenda hêz û îhsanê zaniye bi heman awa û edayî doza parastinê lê kiriye.

Melayê Cizîrî ji bo dabînkirina parastina Mîr, di dirêjahiya qesîdeya xwe de bi sîtayîş wesfên Mîr dide û ji bo pesnên xwe bihêz bike Mîr dişibîne hin hikumdarên mezin û efsanewî. Di qesîdeyê de hatiye ku Mîr bi dadperweriya xwe mîna Nûşîrewan, bi comerdiya xwe mîna Hatem, bi hukm û desthilata xwe mîna Eskender û Fexfûr, bi bezm û kamiraniya xwe mîna Cem, bi bereketa xwe ya manewî mîna Rûhilqudus, bi temendirêjiya xwe mîna Xizir û Nûh, bi zêdebûn û firehiya mulkê xwe mîna Zulqerneyn û bi karîgeriya desthilata xwe ya efsanewî mîna Suleyman pêxember e. Herweha Mîr wusa bihêz û dilêr e ku Xusro û Şapûr ne bendê wî 
ne, belku bendê kurê wî ne. Bêguman mezinkirina hikumdaran armanca sereke ya qesîdeyan e û şibandina wan bi şah û padîşahên berê yek ji taybetmendiyên giştî yên edebiyata klasîk a îslamî ye. Lewra şibandina hikumdarekî bi hikumdarên berê vedigere serdema Emewiyan û li gor ku Tanpınar ji Teberî radigihîne cara pêşî xelîfeyê Emewî Yezîd xwe bi padîșahên berê şibandiye û gotiye: “Ez kurê Merwan û Xusrev im. Kalê min Qeyserê Bîzansê ye û Xaqanê tirk bapîrê min e” (Tanpınar, 2010: 25). Mela jî li ser vê rêbazê weha salixê Mîrê xwe dide:

Paşê Newşîrwan dibêm dê hakimê 'adil tu yî

Mislê Hatim dê bi danê der cîhan meşhûrî bî

Ma Cizîrê şubhê darê textê heft iqlîmi bit

Hem bi hukm û seltenet Eskender û Fexfûrî bî

Mislê Cem cama zerîn xalî nebî te j’badeyê

Da ji xemra şadimanî daîma mexmûri bî

$\cdots$

Çendekî şîrînpuser derbendê dîwana te bin

Bendê şapûrê te bin ta Xusro û Şapûrî bî

Şubhetê Rûhilqudus 'erdê tu pê lê dayinî

Sebze û reyhan û nesrîn û gulê menqûri bî

Ma te 'umrê Xedr û Nûh û mulkê Zulqerneyn bitin

Gunbeda çerxê melemme' her bi te me'mûri bî (r. 225-226)

Ji bilî şibandina şah û padîşahên berê, Mela ji bo berçavkirina hêz û desthilata Mîr û hêza wî ya cengê gelek caran ji objeyên asîmanî jî sûd werdigire û bilindiya Mîr bi alegoriya unsurên asîmanî berçav dike. Ji ber vê jî Mela dema behsa patronê xwe dike weha nîşan dide ku di serdema cengê de stêrkên Zuhre û Kêwanê dikevin bin rikêba wî, heft stêrk û neh gêrestêrk ji bo kar û xizmetê li dora wî digerin û dema dest bi fetha ezel jî dike taca serê wî wek rojê birûsk vedide û stêrk li dora vê tacê çerx didin. 
Her kinarê pê ve wergêrî 'inanê himmetê

Zuhre bî peykê te û Kêwan rikêbdarê te bî

Seb'eyê seyyare û neh çerxê sergerdan bi vê

Girdiş û dewrê 'eceb der xizmet û karê te bî

Lami'ê fetha ezel berqê ji ber tacê te dit

Kewkeba Se‘da ebed necmek ji seyyarê te bî (r. 221)

Li gor Mela ji ber vê hêza asîmanî û bêwêne kî li dijî fermanên Mîr derkeve weku findekê mehkûmê helandinê ye û nikare xwe ji ber derbên şûrên wî rizgar bike. Eger ew kes şahbaz be jî nikare xwe ji tora desthilata Mîr rizgar bike û dê bibe nêçîra wî. Ji ber vê jî li gor Mela her kesê ku xwedî aqil be divê bikeve bin xizmeta Mîr û dewlet û xweşbextiyê li ber dergehê wî bigere ku çavkaniya lutf û îstîxnayê ye.

Ê ji emrê te‘y mukerrem serkeşî kit şubhê şem‘

Ber serê tîxê te û meqtûlê mûkarê te bî

Şahibaz er çendî perwazê bi bala bêt û ret

Dê di nêv tora te bêt û seydê şunqarê te bî

Her serê dewlet hebit dê her di nêv benda te bit

Her kesê 'aqil bitin dê her di çokarê te bî

Ê divêt azade bit dê çehvinêr lutfa te bit

Her çi istixna di dil ber minnet û parê te bî

Her kesê qestek di dil dê qestê dergahê te kit

Ê di xatir ercû kit dê her ricakarê te bî (r. 222-223)

Li hember vê hêza Mîr, Mela jî mîna herkesî dixwaze bikeve bin hîmayeya wî û ji aliyê Mîr ve bê qebûlkirin. Lewra Mela li hember vê hêz û comerdiya nedîtî Mîr weku Suleyman pêxember û xwe jî di hafa wî de weku mûrekî dibîne. Piştî ku Mela 
bi xizmeta Mîr şa dibe, dibêje ew kesê mîna teyrê goyîn nekeve bin xizmeta Mîr dê şerpeze bibe û têk biçe. Aşkera ye ku Mela helbestvanan dişibîne teyrê goyîn, lewra helbestvan jî mîna teyrê goyîn bi helbestên xwe di hizura Mîr de dinalin û dermanê nalîna wan jî tenê parastin û tewecuha Mîr e.

Ger çi der dîwanê hedret pur heqîr în şubhê mûr

Çeşmê te çeşmê Suleymanî bi halê mûri bî (r. 226)

Ê ne wek goy bê ser û pa bêt di benda xizmetê

Ma di çewgana te her perkende û meqhûrî bî (r. 226)

Ji ber vê, Mela hêvî dike ku her di xizmeta Mîr de be, sînga xwe jê re bike deryaya gotinên mirarî û pê pesnê wî bide. Loma jî amadehiya xwe nîşan dide ku tu caran li ber dergehê dewleta Mîr winda nebe û her di bin fermana wî de bi “me'mûrî" bimîne.

Her di medhê te'w senayê sîne û qelbê Melê

Bê tafawut qulzema purlu'luwê mensûrî bî

J'asitanê dewletê xaib nebî carek Mela

Da ji fermanê mukerrem dem bi dem me'mûrî bî (r. 226)

Qest û daxwaza Melê daîm ji can û dil ev e

Her di benda xizmetê pêșdestê dîdarê te bî (r. 223)

Diyar e, Melayê Cizîrî bi van her du qesîdeyên xwe di çarçoveya mezmûnên hevbeş ên şaristaniya îslamê de pesnê lehengî, hêzdarî, dadperwerî û ciwamêriya patronê xwe dide û doza parastinê lê dike. Lê dema vê dike di her du qesîdeyên xwe de jî tenê cih dide beşa medhiyeyê û beșên din ên mîna nesîb, texezzul, girîzgah û fexriyeyê la dide. Ev jî ji ber vê çendê ye ku beşa medihiyeyê ji beşên din cudatir rasterast berê xwe dide patron û pesnê wî dide. Lewra bi gotina Banarlı bi derbasbûna demê re ev beş dibe armanca sereke ya qesîdeyan (Banarlı, 1997: 188) û hin helbestvanên mîna Melayê Cizîrî pêwîstî bi beșên lawekî yên din ên qesîdeyê nabînin û qesîdeyên xwe bi vê beșê sînordar dikin. 


\title{
Hogiriya Mîr û Mela
}

Helbesta sêyem a ku peywendiya Melayê Cizîrî û mîran nîşan dide danberheva Mîr û Mela ye. Ev helbesta gotûbêjî ji aliyê Mîr Umadeddîn ${ }^{1}$ û Melayê Cizîrî ve hatiye danîn û asta nêzîkbûna Mela nîşan dide digel desthilatdaran. Bêguman di nav sîstema patronajê de ji bo helbestvanekî îltîfata herî mezin hogiriya (musahibî) hikumdaran û rêvebiran e. Musahibî tê wateya şêwirmendiya hikumdar û hevaltiya razên wî yên şexsî û hevrêtiya wî ya jiyanê (İnalcık, 2010: 24). Di vê wateyê de danberheva Mîr û Mela vê nîșan dide ku Mela di kariyera xwe ya edebî de gihîștiye pileyeke bilind ku ew jî hevaltiya digel mîran e. Li aliyê din danberheva Mîr û Mela nîşaneya herî bihêz a peywendiya Melayê Cizîrî ye digel serayê. Ev peywendî ew çend bihêz û xurt e ku dema Mela wefat jî dike ev peywendiya xurt xwe nîşan dide û Mela di nav goristana taybet a malbata Mîr de tê veșartin û wek endamekî malbata Mîr dibe mezherê îltîfateke taybet.

Danberheva Mîr û Mela bi gotin û silava Mela dest pê dike. Lewra Mîr ji ber hêz û otorîteya xwe muqîm e û her kes û her tişt li dora wî digerin. Mela jî weku piraniya helbestvanên serdema xwe hewcedar û daxwazkarê îhsana Mîr e û ji bo xwe bigihîne xizmeta Mîr û ji aliyê wî ve bê qebûlkirin divê cara pêşî ew li Mîr silav bike.

Mela:

\author{
Selama min senaxwanî sehergeh gewher'efşan bit \\ Bi sûret emrê Subhanî ser elqabê zer'efşan bit \\ Bi xizmet 'erdê sultanî 'ebîr û 'enber'efșanî
}

Mîr:

\begin{abstract}
Selama sani'ê Qadir Mela da pê mu'etter bî
Muferreh bit me lê xatir peyapey lê mukerrer bî

Ji cama xatirê 'atir me jê ayîne enwer bî (r. 302)
\end{abstract}

\footnotetext{
Mîna muxatebên qesîdeyên Mela li ser Mîr Umadeddîn jî di çavkaniyan de îddîayên ciyawaz hene. Merûf Xeznedar ji ber ku derbarê Mîr Umadeddîn de agahiyên dîrokî bi dest naxe her du beşên vê helbestê jî aîdê Mela dizane û Mîr Umadeddîn kesekî xiyalî dihesibîne (Xeznedar, 2010: 346-347). Abdullah Yașın diyar dike ku Mîr Umadeddîn kurê Mîr Şerefê Duyem e û heval û şagirdê Melayê Cizîrî ye (Yaşın, 2007: 53-54). Lê li ser kêla Mîr Umadeddînê kurê Şerefê Botî dîroka 914ê koçî hatiye nivîsîn û ev jî nîşan dide ku Mîr Umadeddîn di 1508/1509ê zayînî de miriye û ev jî beriya jidayîkbûna Melayê Cizîrî ye. Li gor Selefî û Doskî jî Mîr Umadeddîn mîrekî ji mîrên Hekariyê ye û xwendekarê Melayê Cizîrî bûye (Selefî-Doskî, 2008: 76). Li ser destnivîsa Taha Ebabekir a dîwana Melayê Cizîrî jî̀ navê mîrê ku bi digel Mela helbest gotiye "Emîr Emadeddîn el ‘Ebbasî-yi’l Hekkarî quddîse sirruhuma” hatiye nivîsîn (Amêdî, 1998: 53). Doskî di xebateke xwe ya çapnebûyî de li ser Mîr Umadeddîn bêtir agahî dide û bi palpiştiya du destnivîsên dîwana Mela (Destnivîsa Mihemed Esmerê Xoşabî -1872- û destnivîsa Mihemed Sebriyê kurê Mela Ebdulfettahê Herşinî -1923-) diyar dike ku Mîr Umadeddîn yek ji mîrên Hekariyê bûye, hevaltiya Melayê Cizîrî kiriye, bi nasnavê Sebûrî helbest nivîsîne û heta niha heft helbestên wî bi dest ketine (Doskî, 24-25). Bi vî awayî diyar dibe ku ev mîr ji mîrên Hekariyê ye û bi gotina Bruinessen (Bruinessen, 2033: 251) dibe ku li gor taybetmendiyên wê serdemê weku mêvan yan jî șêwirmend di seraya Cizîra Botan de mabe û peywendiya wî bi Melayê Cizîî re çê bûbe.
} 
Herçend Mîr bi vê danberhevê Mela muxateb qebûl kiriye û qedrê wî girtiye jî, hiyerarşiya navbera Mîr û Mela di seranserî danberhevê de bi awayekî aşkera xwe nîşan dide. Di dirêjahiya vê gotûbêjê de digel pesindana Mela, Mîr bixwe jî pesnê xwe dide. Mîr wesf û taybetmendiyên xwe yên hikumdariyê di warê îrfan û eşqê de jî bi bîr tîne û bi vî awayî bi şanazî behsa hêza xwe ya madî û manewî dike.

Mîr:

Ji neş’a badeya kasê bi zat ez xerqê 'urfan im

Bi wê camê bi wê tasê sifetkisra we xaqan im

Ji berqa xemzeelmasê li textê dil Suleyman im (r. 304)

Di perwazê humadeng în me ser da tacê îqbalê

Şehê Keyxusro û Zeng în serefraz în di vî halê

Werîn saqî meya rengîn me dil maye di vê qalê (r. 308)

Mela li beramber mezinahî û şanaziya Mîr gelek dilnizim e û xwe li ber dergehê wî axa bin lingan dizane. Mela dibêje eger ez biçim ser felekan jî dîsa di benda Mîr de mîna nêçîrekî me û Mîr kengê bixwaze dikare min nêçîr bike. Çawa Mîr xwe di hikumranî û eşqê de xwedan hêz û desthilat dizane, Mela jî bi heman şêwe wesfên wî yên desthilatdariyê di warê gotin û edebiyatê de jî bi bîr tîne û bi van gotinên xwe şanaziya Mîr dupat dike.

Mela:

Di rê da xakê dergah im belê ewwel ji vê xakê

Bila bê paye û cah im me pê çû ferqê eflakê

Şigarek derxurê şah im di wî bendê di fitrakê

Di îqlîmê suxen xaqan rewanbexş û şekerrêz î

Nehin wek te di afaqan bi can ra 'enber'amêz î

Ji sîmînsa‘id û saqan bi sehharî guherrêz î (r. 308-309)

Mîr weku meqamê pesendkirin û qebûlê, Mela di huner û edebiyatê de melevan û sihêrbazê deryaya gotinên mirarî û ji Misirê heta Qezwînê weku xwedî helbestên şekerbar wesif dike ku dikare di carekê de sed helbestî li hev bîne. Herweha Mîr di dawiya vê danberhevê de ji ber hunera bilind a Mela wî weku ustad qebûl dike. Ev pesindan jî nîşan didin ku cih û pileya Mela di nezera Mîr de gelek bilind e û Mela helbestvanê herî mezin ê seraya Cizîra Botan e. 


\section{Mîr:}

Bi xewwasî bi sehharî te dur anîn ji behreynê

Ji nezma te şekerbarî ji Misrê ta bi Qezwînê

Bi diqqet bîn sed eş‘arî dibêjî terfetil'eynê

Di baxê lefz û me'nayê suxen min serwî azad e

Ji îmla û ji înşayê me lewhê dil numa sade

Ji husnê rewneqek dayê ku Şeyx Ehmed me ustad e (r. 310)

Mela di dawiya danberhevê de rasterast diyar dike ku di bin xizmeta Mîr Umadîn de ye û di qulzuma wî ya nîmetan de gewheran berhev dike. Yanî bi saya wî dikare van gotinên mîna dur û mircanan li hev bîne. Ev jî bi awayekî aşkera nîşan dide ku Mela helbestvanekî serayê ye û di bin sîbera seraya mîran de kariye hunera xwe bîne holê.

\section{Mela:}

Ji behra qulzuma mîran bi xewwasî guherçîn im

Di behsa 'ilm û tefsîran tu deryayan we nabînim

Ji mîr û begler û çîran xulamê mîr Umadîn im (r. 310)

\section{Xurûra Mîr û Șanaziya Mela}

Melayê Cizîrî ji ber peywendiya wî ya bihêz digel mîrên seraya Cizîra Botan û weku helbestvanê vê serayê dema di helbestên xwe de şanazî bi hunera xwe dike di heman demê de xurûra seraya Cizîra Botan jî temsîl dike. Bo nimûne dema ji ber dizîna helbestên xwe rexne li Melayê Finikî digire, Finika navçeya Mîrektiya Cizîra Botan jî li hember Cizîrê biçûk dixe. Ev malika Melayê Cizîrî tenê reqabeta di navbera du helbestvanan destnîşan nake, di heman demê de milmilaneya navbera paytext û navçeyan jî nîşan dide. Lewra di Serdema Navîn de di nav sîstemên rêvebiriyên monarşîk de tu carî navendê nedihişt bajarên biçûk ên derûdor li hember paytext bihêz bibin û hêza reqabetê di xwe de bibînin (Kılıçbay, 2000: 116). Ji ber vê jî Melayê Cizîrî li ser navê seraya Cizîrê di şexsê Melayê Finikî de Finika navçeya herî bihêz a Mîrektiya Cizîra Botan biçûk dixe û bi vî awayî hêza paytexta patronê xwe nîşan dide.

Tu dizanî Finika te ne mekanê xezelan e

Çi buha tîne meta'ê te eya bê ser û ber (r. 300) 
Di Serdema Navîn de ji ber ku desthilatdarên îslamî tevî berpirsiyariyên dunyewî berpirsiyariyên uxrewî jî hebûn û hem dîn û hem dunya temsîl dikirin, karîgeriya îdeolojiya dînî li ser wan gelek bû. Ji ber vê çendê hikumdaran bi qasî helbestên pesindana desthilata xwe ji helbestên dînî û tesewufî jî hez dikirin. Loma jî Melayê Cizîrî dema xwe di eşqê de weku arifekî bêwêne nîşan dide hem dixwaze karîgeriya xwe li ser serayê û rêvebiran zêde bike hem jî ji hêla manewî ve dixwaze seray û paytexta Mîrê xwe bihêz nîșan bide. Mela xwe weku "arifê zeman û muftiyê eşqê" dibîne. Çawa ku sed mela û musteîdên li derûdora wî nikarin muemmaya eşqê hel bikin û ew çend îlmên wan nîne, Me'rufê Kerxî jî hewcedarê îlmê Mela ye. Loma jî Me'ruf divê ji Kerxê bê Cizîrê û li ber destê Mela tedrîs bibîne. Lewra Mela xwe li ser çiyayê Qendîlê weku fîlê eşqê dibîne, di nav baxê Botan de gulê herî bijarte ew e, ne tenê li Botan li seranserî Kurdistanê çiraya wî tarîtiyan ronî dike.

Kerixîn em di qiyamê me ji dil perde dirand

'Arifê weqt im û Me'rûfi bila bête ji Kerx (r. 84)

Tu j'Mela her bipirs esrarê 'işqê hel dikit

Vê mu'emmayê çi zanin sed mela û muste‘îd (r. 88)

'Aşiqê mes'elexwahî were em muftiyê 'işq în

Destekî sunnet e tê da di yekî nessê kîtab e (r. 181)

Tu narê firqetê zanî dikarim ez tehemmul kim

Diyarê kohê Qendîl im meger fîl im di 'işqê da (r. 28)

Gulê baxê Îremê Bohtan im

Şebçiraxê şebê Kurdistan im

Çi tebî'etbeşer û insan im

Lillahîlhemd çi ‘alîşan im

Di riya yar li rêza san im

Lew di iqlîmê suxen xaqan im (r. 273)

Mela çawa ku xwe di eșqê û îlmên manewî de arif dizane di heman demê de xwe di hunera helbestê de jî pêşeng û cîhangîr dizane. Lewra helbesta wî di rewaniyê de mîna avê diherike, gotinên wî mîna lu'lu'an in, eda û awayê helbesta wî di nav husneke temam de xwedî sihr û efsûn e. Ji ber vê çendê jî xwe di warê gotin û edebê de mîrekî cîhangîr û serdarê helbestvanan dide zanîn, Ferruxê Sîstanî li ber xwe ferxê helbestê dibîne û helbesta xwe ji ya Hafizê Şîrazî çêtir dizane û îddîa dike ku helbestên wî pêdivî bi helbestên Şîrazî nehiştine. 
Husnê edaya te Mela her kî dî

Sehne lehu enneke 'eynu'l-fisah (r. 72)

Abê rewan min diye şi'ra Mela

Yunkiru li'I-mai li sûi'l-mizac (r. 68)

Şi'ra te Mela sihrê şekerrêz e bi mu'ciz

Zanim ji lebê le'lî te ev lefz û eda girt (r. 49)

Pîrê şe‘ar e di şi’rê we Melê şalifiroş

Tu nîşan min mede Ferxî ku li nik min bûye ferx (r. 84)

Ger lu'lu'ê mensûrî ji nezmê tu dixwazî

Wer şi'rê Melê bîn te bi Şîrazî çi hacet (r. 51)

Di iqlîmê suxen mîr im di şi'rê de cehangîr im

We ye'lû mewkibe'l-‘uşşaqi e’lamî we rayatî (r. 234)

Bi van mînakan derdikeve ku Melayê Cizîrî wek helbestvanekî mezin ê seraya Cizîra Botan bi helbestên xwe yên pesindariyê ji aliyekî ve dixwaze hêza hunera xwe nîşanî patronê xwe bide ji aliyê din ve jî li hember serayên din nûnertiya xurûra desthilatdarên seraya Cizîra Botan bike. Ev jî dibe sedem ku em malikên xwe pesindana Mela ji wateyeke nerîtî cudatir di çarçoveya patronaja edebî de binirxînin.

\section{Encam}

Di encama van nirxandinan de em dikarin bibêjin ku patronaja edebî weku rêyeke berhemanîna edebî di nav sîstemeke patrîmonyal de derdikeve holê û di her serdemekê de bi dirûvekî taybet xwe nîșan dide. Di bingeha vê sîstemê de hikumdar (patron) heye ku xwedîhêz û desthilateke mezin e û bi cazîbeya hêza xwe helbestvan û edîban li dora xwe kom dike û dibe sedema berhemanîna edebiyatek ku tê de hêvî û daxwazên wîberceste bibin. Ji bilî vê, parastina helbestvan û edîban li hember desthilatdarên dijber hêzeke manewî dibexşîne patron û parêzvanên van kesan da ku navûdengên wan bi hêza hunera helbestvanan bi başî û şikomendî belav bibe.

Ji destpêka avakirina bajar-dewletan heta serdema modern di navenda vê sîstema patrîmonyal de hikumdar hebin jî car bi car li tenişt wan; wezîr, mîr û rayedarên din jî bi rola parêzvanî û patronaja edebî radibin. Melayê Cizîrî jî di nav Mîrektiya Cizîra Botan de ku hikumeteke navçeyî ya dewleta Osmanî bû, herweku 
ji hin helbestên wî jî diyar dibe, dikeve bin xizmeta Mîrê Cizîra Botan û pesnê desthilat û kesayetiya wî ya şikomend dide. Herçend li ser muxatebê qesîdeyên Melayê Cizîrî di nav lêkoleran de hizrên cuda derketibin jî bi raya me kesê ku Melayê Cizîrî di her du qesîdeyên xwe de pesnê wî dide Mîr Şerefê Sêyem ê mîrê Cizîra Botan e û Mîr Umadînê ku pê re danberheveke helbestî jî çê dike yek ji mîrên hînterlanda Mîrektiya Cizîra Botan e.

Melayê Cizîrî wek normeke qesîdeyên wê serdemê patronê xwe bi teşbîh û mezmûnên hevbeș ên edebiyata klasîk a îslamî dipesenîne ku di serfirazî, comerdî û hêzê de ji hemû kesayetên efsanewî derbas dike û bi hêz û şikomendiya xwe hemû cîhanê li dora roja desthilata xwe de digerîne. Li hember vê xwe jî hewcedar û dildarê vê hêza wî dibîne û hêvî dike ku wî di seraya xwe de wek bende qebûl bike da ku ew jî bigihîje miradê xwe. Bi vî awayî Melayê Cizîrî mîna helbestvanên din ên serayê li gor binyad û naveroka qesîdeyan pesnê patronê xwe dide û mînakeke patronaja edebî pêşkêșî me dike di edebiyata kurdî de. Ji bilî vê, Melayê Cizîrî bi danberheva xwe ya helbestî ya digel Mîr Umadîn jî nîşan dide ku di têkiliyên xwe yên patronajê de gelek pêşketiye û hatiye asta wê yekê ku digel mîrekî helbesteke hevbeș binivîse û di vê helbestê de ji aliyê mîr ve pesnê hostetî û hunera wî bê dayîn. Di vê çarçoveyê de jî Mela di çendîn helbestên xwe de diyar dike ku wî bi hunera xwe ji helbestvanên navdarên mîna Hafizê Şîrazî û Ferrûxê Sîstanî derbas kiriye û bi vê şanaziyê jî xurûra seraya Mîrê xwe bilind dike.

\section{Çavkanî}

Amêdî, S. B. (1998). Hozanvanêt Kurd (Z. Zinar, Tîpguhêzî). Stockholm: Pencînar.

Banarlı, N. S. (1997). Resimli Türk Edebiyatı Tarihi I, İstanbul: Millî Eğitim Basımevi.

Bedlîsî, Ş. (2007). Şerefname (Z. Avci, Wer.). Stenbol: Avesta.

Bruinessen, M. V. (2003). Ağa, Şeyh, Devlet, İstanbul: İletişim Yayınları.

Çelebî, E. (?). Seyahatname (R. Dankoff-S. A. Kahraman- Y. Dalı, Amd.). Yapı Kredi Yayınları.

Cizîrî, M. (2010). Dîwan (S. Dilovan Amd.). İstanbul: Nûbihar.

Doru, M. N. (2016). Melayê Cizîrî Felsefî ve Tasavvufî Görüşleri (Çapa Duyem). İstanbul: Nûbihar.

Doskî, T.î. Baxê Îrem (Pirtûka Çapnebûyî).

Ebûş, F. H. (2004). El Medîne Kurdiye, Erbîl: Spîrêz.

Ergün, Z. (2014). Bajar-Edebiyat û Cizîra Botan, İstanbul: Nûbihar.

Hejar (1361). Dîwanî Rebbanî Şeyx Ehmedî Cizîrî, Tehran: Siruş.

Hodgson, M.G.S. (1993). İslam'ın Serüveni, İstanbul: İz Yayıncılık.

Kılıçbay, M. A. (2000). Şehirler ve Kentler (Çapa Duyem). Ankara: İmge Kitabevi. 
Lapidus, I. M. (2005). İslam Toplumları Tarihi (Y. Aktay, Wer.). İstanbul: İletişim Yayınları.

İbn Haldun (1991). Mukaddime (S. Uludağ, Amd.). İstanbul: Dergâh Yayınları.

İnalcık, H. (2010). Şair ve Patron (Çapa Sêyem). Ankara: Doğu Batı Yayınları.

İnalcık, H. (2017). Has-bağçede 'Ayş û Tarab Nedimler Şairler Mutrîbler (Çapa Sêyem). İstanbul: Türkiye İş Bankası Kültür Yayınları.

Makdisi, G. (2009). İslam'ın Klasik Çağında ve Hıristiyan Batı'da Beșeri Ilimler (H. T. Başoğlu). İstanbul: Klasik Yayınları.

Mumford, L. (2007). Tarih Boyunca Kent (G. Koca-T. Tosun, Wer.). İstanbul: Ayrıntı Yayınları.

Ocak, A. Y. (2011). Ortaçağlar Anadolu'sunda İslam'ın Ayak İzleri Selçuklu Dönemi (Çapa Duyem). İstanbul: Kitap Yayınevi.

Secadî, E. (1952). Mêjûy Edebî Kurdî, Bexda: Çapxaney Mearîf.

Selefî, H. A.-Doskî, T. î. (2008). Mu'cemu'ş-Şu'erai'l-Kurd, Duhok: Spîrêz.

Sevgen, N. (1982). Doğu ve Güneydoğu Anadolu'da Türk Beylikleri (Ş. K. SeferoğluH. K. Türközü, Amd.). Ankara: Türk Kültürünü Araştırma Enstitüsü.

ö 170 Tanpınar, A. H. (2010). XIX. Asır Türk Edebiyatı Tarihi (Çapa Heştem). İstanbul: Yapı Kredi Yayınları.

Varlî, E. M. M. (Hoko) X. (1997). Dîroka Dugelên Kurdan, İstanbul: Hoşka Weșan û Lêkolîna Sîpan.

Wellek, R.-Warren, A. (2016). Edebiyat Teorisi (Ö. F. Huyugüzel, Wer.). İstanbul: Dergah Yayınları.

Xeznedar, M. (2010). Mêjûy Edebî Kurdî, Hewlêr: Dezgay Çap û Bellawkirawey Aras. Yaşın, A. (2007). Tarih Kültür ve Cizre, Ankara.

Zivingî, M. M. (?) “Muqeddîme” el-Iqdîl Cewherî fî Şerhî Dîwanî Şeyxî’l Cezerî, Qamişlî. 